\title{
Biological Restoration to Restore a Extensively Damaged Tooth: A Case Report
}

\author{
Mahesh Motlani ${ }^{1}$, Pragya Jaiswal2 ${ }^{2}$, Aditi Jain ${ }^{3^{*}}$ \\ 1Senior Lecturer, Department of Conservative Dentistry \& Endodontics, \\ Chhattisgarh Dental College \& Research Institute, Rajnandgaon, Chhattisgarh, India. \\ ${ }^{2}$ Associate Professor, Department of Dentistry, \\ Government Medical College, Rajnandgaon, Chhattisgarh, India. \\ ${ }^{3}$ Senior Lecturer, Department of Conservative Dentistry \& Endodontics, \\ Maitri Dental College \& Research Center, Anjora, Chhattisgarh, India.
}

\begin{abstract}
Trauma to anterior teeth of a young patient is an agonizing experience, which requires instantaneous attentiveness not only because of damage to dentition but also because of the emotional impact on both the patient and parents. Many commercially post systems are available but none of them meet all the ideal biological and mechanical properties. In this context a "Biological Post" serves as a good option for intraradicular rehabilitation of a fractured tooth by virtue of its biomimetic property. This clinical case report addresses the esthetic and functional restoration of a complex crown fracture of left maxillary lateral incisor in a young patient using "Biological Post" made from a freshly extracted, intact human canine in single visit. Because of several advantages dentin post can be considered as an innovative substitute technique to re-establish the functions and esthetics of the patient in single visit of an extensively mutilated tooth.
\end{abstract}

\section{INTRODUCTION}

Fracture of maxillary central and lateral incisors is the most common dental injury seen because of their positioning in the dental arch. The most frequent causes of trauma are road accidents, sports \& violence. Several methods and procedures were employed to restore fractured teeth. An interdisciplinary approach is the key. Biological restoration is a fragment reattachment procedure using fragment obtained from extracted human teeth. Also known as homogenous fragment bonding. Concept of attaching natural tooth fragment was introduced when Chosak \& Eidelman used a cast post \& conventional cement to reattach an anterior crown segment. ${ }^{1}$ Term "Biological restoration" introduced by Santos \& Bianchi to describe an alternative technique that used adhesive capabilities of materials in combination with strategic placement of parts of extracted human teeth. ${ }^{1}$ These recent developments in restorative materials conjunction with advances in adhesive protocols many a times turn out to be expensive and technique sensitive and also require expertise of operator. Moreover, none of the commercially available posts meet all the ideal biological and mechanical properties. In this context a tooth fragment reattachment procedure presents several advantages such as conservative,
Keywords: Biological dentin post, Biomimetic property, Bio- reconstruction, Fractured incisor.

\section{${ }^{*}$ Correspondence to:}

Dr. Aditi Jain MDS

Senior Lecturer,

Department of Conservative Dentistry \& Endodontics, Maitri Dental College \& Research Center,

Anjora, Chhattisgarh, India.

\section{Article History:}

Received: 28-08-2016, Revised: 19-09-2016, Accepted: 15-10-2016

\begin{tabular}{|l|c|}
\hline \multicolumn{2}{|c|}{ Access this article online } \\
\hline $\begin{array}{l}\text { Website: } \\
\text { www.ijmrp.com }\end{array}$ & Quick Response code \\
\hline DOI: & \\
10.21276/ijmrp.2016.2.6.024 & \\
\hline
\end{tabular}

good and long lasting esthetics because tooth's original anatomic form, color, and surface texture are maintained) \& cost effective. ${ }^{2}$ This article reports a case with coronal tooth fracture that was successfully treated using biological post for tooth fragment reattachment.

\section{CASE DISCUSSION}

A 19-year-old male patient reported to the department of Conservative Dentistry and Endodontics, Chhattisgarh Dental College, with a complaint of fractured left maxillary lateral incisor. The patient's medical history was noncontributory. Clinical examination revealed Ellis class III fracture with right maxillary lateral incisor (Fig 1). There was no soft tissue injury or swelling. Tooth was tender. Radiographic examination revealed a horizontal fracture of the left maxillary lateral incisor involving enamel and dentin with exposure of the pulp (Fig 1). The patient's parents were informed about the advantages and disadvantages of all the feasible treatment options. Having agreed for the biological post, the proposed treatment plan included intraradicular biological post, followed by reattachment of fragment. Prior to the execution of the proposed treatment, a written consent form authorizing the 
completion of the procedure, as the dentin post is made from extracted teeth. Local anesthesia was administered followed by the removal of complete pulp tissue and fragment using a forceps without damage and preserved in a physiological saline solution during clinical procedure so as to maintain its hydration \& natural color (Fig 2). Tooth was isolated using rubber dam to ensure

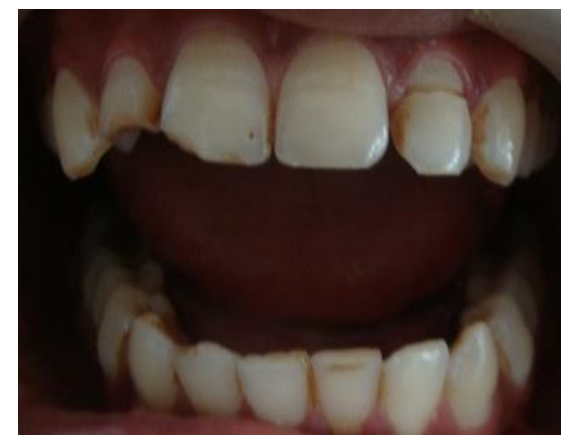

Fig 1: Preoperative clinical \& radiographic examination revealed Ellis class III fracture with maxillary lateral incisor

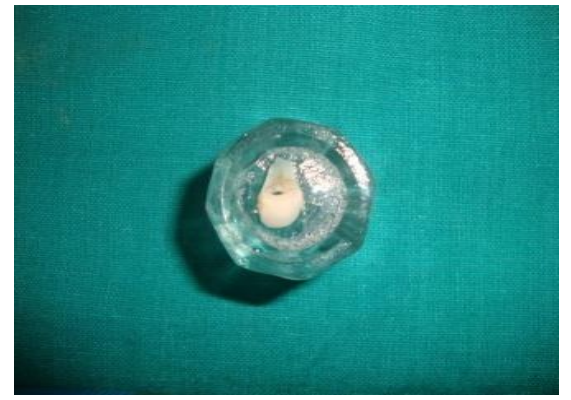

Fig 2: Fractured fragment removed and stored in normal physiologic saline

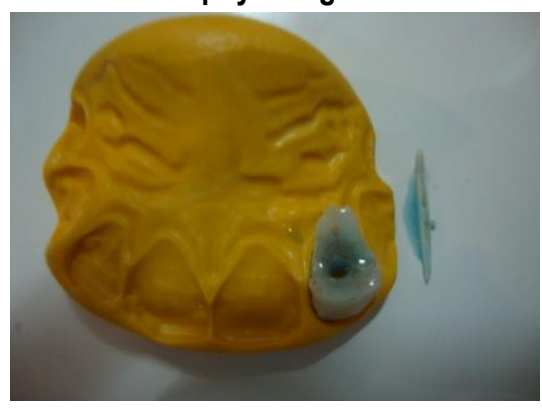

Fig 4: Post \& the inner portion of the coronal fragment was etched and bonded to the tooth using dual cured resin luting cement (Rely $X^{\mathrm{TM} U 200-3 M}$ ESPE).

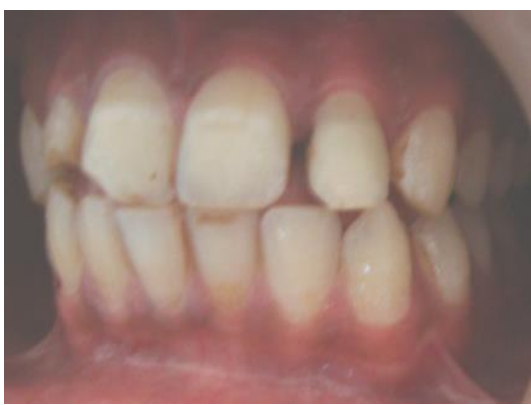

Fig 5: Post operative image moisture control. Complete pulp tissue was removed, working length was determined using electronic apex locator and cleaning and shaping was done step - back technique, for irrigation $2.5 \%$ sodium hypochlorite and saline were used, followed by sectional obturation i.e. Gutta Percha from the canal was removed leaving apical $5 \mathrm{~mm}$.

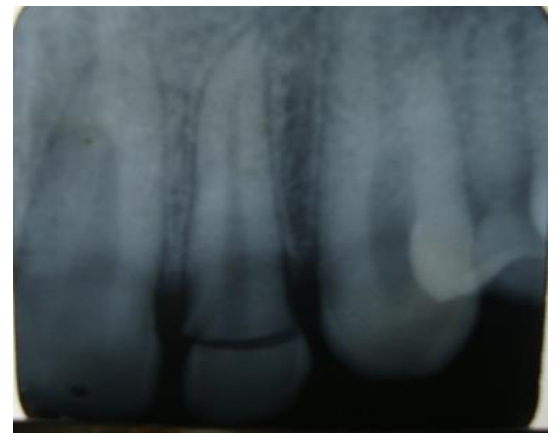

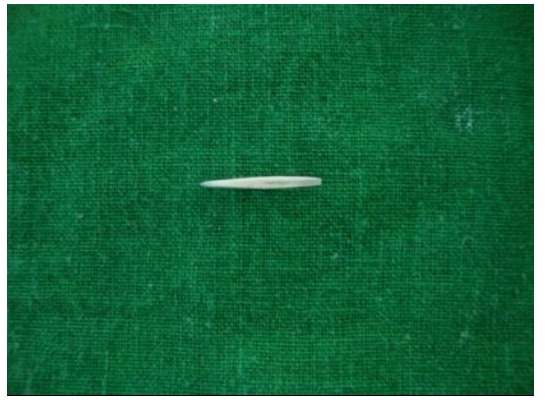

Fig 3: Biological post made from the freshly extracted intact maxillary canine

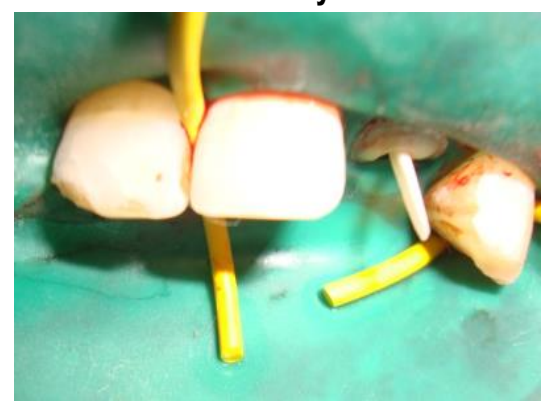

\section{Fabrication of biological post}

A freshly extracted, intact maxillary canine tooth was chosen and subjected to autoclaving at $1210 \mathrm{C}$ for 15 minutes under 30 psi. The tooth was then sectioned mesio distally along the long axis using a diamond disk (Fig 3). The direct wax impression of the prepared post space served as a guide for the shape, thickness and length of the post. Using the wax impression, further contouring of the sectioned tooth into a dentin post and core was
Fig 6: One year post-operative review

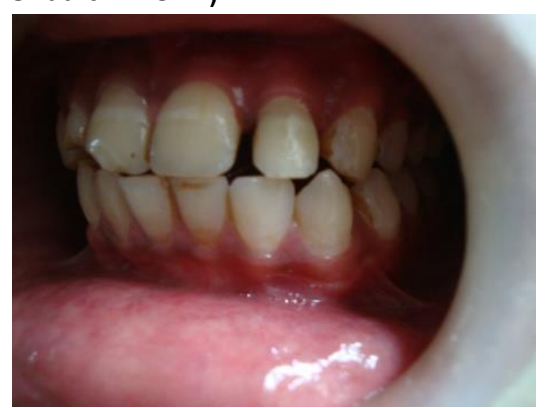

done. The dentin post was tried in the canal and adjusted to the desired length. Space was also prepared in the pulp chamber of the fractured crown fragment for receiving the coronal part of the post. The alignment of the coronal fragment was verified with the post in the canal. The root canal was then etched with $37 \%$ ortho phosphoric acid for 15 seconds, rinsed, blot dried with paper points, and AdperTM Single Bond 2 (etch \& rinse two-step adhesive) bonding agent (3M ESPE, St. Paul, MN, USA) was 
applied using disposable applicator. The post \& inner portion of the coronal fragment was etched and bonded to the tooth using dual cured resin luting cement (Rely X'MU200-3M ESPE) (Fig 4). A composite resin increment was placed over the entire fractured surface, and the fragment was positioned and properly adjusted (Fig 5). Excess was removed \& polishing was done using series of Sof-Lex disks \& (3M ESPE, St. Paul, MN, USA) diamond polishing paste. The occlusion was carefully checked \& adjusted in protrusive \& lateral movements and post-operative instructions are given to the patient in order to prevent extering heavy function on the anterior teeth. Clinical and radiographic examinations were carried out after 3 month, 6, 9 months which revealed satisfactory functional, esthetic, periodontal status and structural performance of the tooth. (Fig 6)

\section{DISCUSSION}

Increased emphasis on the maintenance and preservation of natural dentition combined with an increase in the predictability and effectiveness of endodontic therapy, has made their post endodontic restoration a great challenge in dentistry. ${ }^{3-5}$ These recent advancements in restorative materials conjunction with developments in adhesive technology has resulted in use of natural tooth fragments for management of fractured anterior teeth. ${ }^{6}$

In the present case report, the extracted tooth for preparation of dentin post was selected from a patient scheduled for extraction of an intact maxillary canine due to periodontal disease. The donor was subjected to a thorough review of medical history and routine blood investigations before the initiation of the procedure.

The extracted tooth was properly inspected, cleaned using ultrasonic, stored, and sterilized by autoclaving, ensuring all biosecurity standards. Several studies have reported that autoclaving of extracted teeth may cause a slight reduction in dentin micro hardness, but it does not alter the biomechanical \& physical properties. In the present case, a freshly extracted tooth i.e. maxillary canine was used; the biomechanical properties of the dentine would be well preserved.

Physical properties of biological post closely resembles that of root dentin such as modulus of elasticity, viscoelastic behavior, thermal expansion \& compressive strength. 7,8 Modulus of elasticity of biological post is same as that of root dentin that allow post flexion to mimic tooth flexion so that the post acts as a shock absorber, minimizing fraction of stresses placed on the tooth to the dentinal walls. ${ }^{9}$

Biological post presents several advantages such as patient's selfassurance remains positive due to maintaining natural tooth appearance, it preserves dentin and results in better distribution of forces along the root surface in extensively damaged teeth, low cost \& makes a feasible option in dental institution for the people of low socio economic background.

An in vitro study by Ambica et al. concluded that dentin posts have higher fracture resistance than carbon fiber posts and glass fiber posts. Hence, the use of a biological post is considered a novel technique for the reconstruction of endodontically treated teeth. ${ }^{10}$ Because coronal fractures are the most common form of traumatic dental injuries in the permanent dentition and their supporting structures, it is important to have proper knowledge \& skills of the technique available and their indications, along with risk benefit ratio.

\section{CONCLUSION}

The biological restorations should be considered as a viable technique for reconstruction of extensively mutilated teeth as they provide highly functional and esthetic outcomes. It's a simple, fast, and affordable procedure. Main advantage of using dentin postis, it provides excellent adhesion, strength to the remaining tooth structure, and retention to the crown.

\section{REFERENCES}

1. MT Wanderley, SL Ferreira, CR Rodrigues, LE Rodrigues Filho. Primary anterior tooth restoration using posts with macroretentive elements. Quintessence Int. 1999; 30(6):432-6.

2. AC Ramires-Romito, MT Wanderley, AC Oliveira, JC Imparato, MS Correa. Biologic restoration of primary anterior teeth. Quintessence Int. 2000; 31(6):405-11.

3. FM Mendes, MS De Benedetto, CG del Conte Zardetto, MT Wanderley, MS Correa. Resin composite restoration in primary anterior teeth using short-post technique and strip crowns: a case report. Quintessence Int. 2004;35(9):689-92.

4. PS Mandroli. Biologic restoration of primary anterior teeth: $A$ case report. J Indian Soc Pedo Prev Dent.2003; 21(3):95-97.

5. V Lolayekar N, V Bhat S, S Bhat S. Disinfection methods of extracted human teeth. Oral Health Comm Dent. 2007;1:27-9.

6. S Belli, O Eraslan, G Eskitascioglu, V Karbhari. Monoblocks in root canals: a finite elemental stress analysis study. Int Endod J. 2011; 44(9):817-26.

7. A Kathuria, M Kavitha, S Khetarpal. S. Ex vivo fracture resistance of endodontically treated maxillary central incisors restored with fiber-reinforced composite posts and experimental dentin posts. J Conserv Dent.2011; 14(4):401-05.

8. K Ambica, K Mabendran, S Talwar, M Verma, g Padmini, R Periasamy. Static and fatigue loading of endodontically treated teeth restored with carbon fiber posts, glass fiber posts, and an experimental dentin post system: An in vitro study. J Endod. 2013; 39(1):96-100.

9. Grewal. "Biological Restoration": Root Canal and Coronal Reconstruction. J Esthet Restor Dent. 2010; 22(3):168-77.

10. K Ambica, K Mabendran, S Talwar, M Verma, g Padmini, R Periasamy. Static and fatigue loading of endodontically treated teeth restored with carbon fiber posts, glass fiber posts, and an experimental dentin post system: An in vitro study. J Endod. 2013; 39(1):96-100.

\section{Source of Support: Nil. Conflict of Interest: None Declared.}

Copyright: (c) the author(s) and publisher. IJMRP is an official publication of Ibn Sina Academy of Medieval Medicine \& Sciences, registered in 2001 under Indian Trusts Act, 1882.

This is an open access article distributed under the terms of the Creative Commons Attribution Non-commercial License, which permits unrestricted non-commercial use, distribution, and reproduction in any medium, provided the original work is properly cited.

Cite this article as: Mahesh Motlani, Pragya Jaiswal, Aditi Jain. Biological Restoration to Restore a Extensively Damaged Tooth: A Case Report. Int J Med Res Prof. 2016; 2(6):121-23. DOI:10.21276/ijmrp.2016.2.6.024 